\title{
Por que Voltaire se tornou newtoniano? Por que refletir sobre as ciências?
}

\author{
Véronique Le Ru \\ leru@club-internet.fr \\ Universidade de Reims, Reims, França
}

resumo Meu intuito é tecer algumas considerações sobre a descoberta e relação de Voltaire com o newtonianismo, e a partir daí refletir de maneira mais geral sobre as possibilidades da aproximação entre filosofia e ciência.

palavras-chave Voltaire; newtonianismo; filosofia; ciência; liberdade

Meu propósito é mostrar que, em 1733, aparentemente nada predispunha Voltaire a refletir sobre as ciências e a se tornar newtoniano. Nada e, no entanto, tudo: o coração e suas razões e, sobretudo, o gosto de Voltaire pela filosofia, que significava para ele a busca da verdade, busca que pode se converter em defesa, ou melhor, em combate pela verdade. Em 1733, ele encontra Gabrielle Émilie de Breteuil, a Marquesa du Châtelet. Frequenta com ela o pequeníssimo círculo dos newtonianos na França: Maupertuis, Clairaut et La Condamine. E descobre, graças aos seus novos amigos, uma nova representação do mundo fundada não sobre o espírito de sistema e sobre hipóteses, mas sobre o cálculo e os fatos. A teoria newtoniana da atração se distingue assim, aos olhos de Voltaire, de todos os romances da natureza escritos pelos fazedores de sistemas como Descartes, Malebranche e Leibniz. Não somente Voltaire se põe a estudar assiduamente os Principia mathematica philosophiae naturalis de Newton, publicado em 1687, e que a Marquesa se encarregará de traduzir para o francês, como se instrui sobre todos os debates científicos passados e contemporâneos acerca do sistema do mundo.Voltaire

Recebido em 20 de maio de 2012. Aceito em 29 de agosto de 2012.

Traduzido por Rodrigo Brandão

doispontos, Curitiba, São Carlos, vol. 9, n. 3, p.115-127, dezembro, 2012 
se torna ao mesmo tempo um dos primeiros historiadores das ciências e um notável divulgador de saberes.

No entanto, Voltaire em 1733 não é um cientista, mas um poeta apaixonado por uma marquesa cientista, que o conduz a aprofundar seu interesse por Newton e a tornar a teoria da atração universal acessível a todos os franceses. Voltaire publica em 1738 os Elementos da filosofia de Newton, obra que, de 1738 a 1785, não tem menos do que vinte e seis edições e que torna Newton popular na França. O interesse de Voltaire pela ciência e pela história das ciências (ele faz, para cada problema, uma apresentação das teorias que precederam a explicação newtoniana) reside em defender uma concepção da verdade que não se limite a fronteiras. Eu gostaria de mostrar que Voltaire faz parte daqueles que, pela reflexão sobre as ciências, querem defender um sentido universal do real e do verdadeiro.

Mas comecemos por esta bela história que põe em cena um dos trios mais improváveis da história das ciências: Newton, um dos maiores físicos, Voltaire, aquele que os enciclopedistas chamarão de "patriarca", e, enfim, a marquesa du Châtelet, grande mulher cientista que não somente conhecia o latim, o italiano e o inglês, que cantava muito bem ópera, mas que também traduziu integralmente do latim para o francês os Principia mathematica philosophiae naturalis de Newton e adicionou à sua tradução um comentário explicativo. Voltaire, poeta turbulento e mundano, encontra a Marquesa du Châtelet em 1733, ele tem 39 anos, a Marquesa 27.Voltaire volta da Inglaterra onde teve de se exilar entre 1726 e 1727 após a querela com o duque de Rohan que ameaçou aprisioná-lo na Bastilha. Durante esses dois anos, ele não perdeu tempo, aprendeu inglês, que ensinará à marquesa e que se tornará a língua do amor do casal. E, sobretudo, iniciou-se em Newton seguindo os cursos de Pemberton, amigo e discípulo do grande cientista. Em 1727, Voltaire assiste aos funerais de Newton na Abadia de Westminster e fica fascinado com as honras que lhe foram prestadas. Ao voltar à França, entra em contato com Maupertuis para completar seu conhecimento de Newton. A marquesa também estuda Newton, ela se torna aluna de Maupertuis e até mesmo um pouco mais do que isso.

Após a publicação das ácidas Cartas filosóficas, Voltaire se retira em 1733 para Cirey, na Campanha, no castelo do Marquês du Châtelet, que começa a restaurá-lo. A marquesa, indecisa entre Maupertuis e Voltaire, termina 
por retornar a ele em 1735. Somente com a morte da marquesa em 1749 que terminará o convívio entre os dois. Cirey rapidamente se transforma no centro da propaganda do pensamento newtoniano: lá se seguia as explorações dos cientistas que partiram com o intuito de medir um grau do meridiano na Lapônia e no Peru; lá eram acolhidos os cientistas engajados no combate newtoniano (notadamente Maupertuis e Algarotti, cientista italiano). É também em Cirey que Voltaire redige seus Elementos da Filosofia de Newton e que a Marquesa trabalha na sua tradução e comentário a Newton.

Por que Voltaire se interessou por Newton e por que isto o incitou a refletir sobre as ciências? Certamente pelo amor pela marquesa, para se convencer disso basta citar os primeiros versos do poema dedicatória dos Elementos:

«A Madame la Marquise du Châtelet

Tu m'appelles à toi, vaste et puissant génie,

Minerve de la France, immortelle Émilie,

Disciple de Neuton, et de la vérité,

Tu pénètres mes sens des feux de ta clarté,

Je quitte Melpomène et les jeux du théâtre

Ces combats, ces lauriers dont je fus idolâtre.

De ces triomphes vains mon cœur n'est plus touché»

(VOLTAIRE, 1992, pp.186-187)

Mas a esta razão de coração e de espírito, é preciso acrescentar a certeza de Voltaire de estar investido de um dever. Com efeito, seu interesse por Newton precede seu encontro com Emilie. Ele estava persuadido de que era preciso instruir os franceses sobre a existência bem perto deles, na Inglaterra, de um regime de monarquia que não era absoluta, mas parlamentar, e que favorecia a liberdade intelectual e política, bem como estava convencido de que era preciso introduzir Newton na França e que a verdade deveria triunfar mesmo à custa de Descartes. De 1731 a 1732, ele retoma as Cartas filosóficas que começara a redigir na Inglaterra com este objetivo duplo que ele realiza tão bem; sua obra, julgada escandalosa, é condenada por um decreto do Parlamento e é queimada aos pés da escadaria do Palácio. Com pedido de prisão, Voltaire teve que fugir e se esconder em Cirey. 
Duas das vinte e cinco cartas contidas nessa pequena obra são consagradas a uma comparação entre Newton e Descartes. O tom é comedido, mas sugestivo: é importante, para não ser um simples partidário ouriçado do debate entre cartesianos e newtonianos ou entre franceses e ingleses, ler Newton e não se contentar em ser francês se fixando ao sistema dos turbilhões de Descartes.Voltaire se aproxima aqui de Maupertuis que, em seu Discurso sobre as diferentes figuras dos astros, publicado em 1732, mostra que a hipótese da atração é tão plausível quanto aquela dos turbilhões cartesianos e que, portanto, deve ser levada em consideração. Já o espírito dos Elementos da Filosofia de Newton é outro: ele é abertamente newtoniano e dedicado a atacar os cartesianos.

O propósito de Voltaire é tornar a filosofia de Newton popular. Ele apresenta seu livro como uma introdução ao pensamento de Newton escrito para favorecer o bem comum: "Temos a tarefa de adequar esses Elementos àqueles que não conhecem de Newton e da filosofia senão o nome. A ciência da natureza é um bem que pertence a todos os homens". De fato, Voltaire não entra no detalhe geométrico da obra de Newton, ele se recusa conscientemente tal tarefa menos por incompetência do que por cuidado com o leitor. É sem dúvida isso que explica o sucesso considerável da segunda edição da obra que apareceu em agosto de 1738, em Paris, sucesso que o Abade Prévost comenta nos seguintes termos: "Toda Paris ecoa Newton, toda Paris pronuncia Newton, toda Paris estuda e aprende Newton".

No entanto, Voltaire não procura distrair ou divertir toda Paris, mas instruir os homens de letras. Nesse sentido,Voltaire recusa escrever sua obra da maneira de Fontenelle, ou pior, do abade Pluche. Não se trata de conversar com uma marquesa imaginária sobre a pluralidade dos mundos, num estilo gracioso, nem de se colocar perante o espetáculo da natureza, com o coração cheio de um finalismo ingênuo. Nem a marquesa nem Voltaire gostavam da obra de Fontenelle, que julgavam escrita num estilo florido demais e galante demais. No que se refere a Pluche, zombam abertamente. Se Voltaire dedica sua obra a uma Marquesa, esta não é imaginária: trata-se da marquesa du Châtelet, que vive com ele em Cirey. E se existisse uma marquesa a instruir em Cirey, esta se chamaria Voltaire e não Émilie.

A bem dizer, os Elementos constituem a antítese de um projeto de vulgarização mundana. O prefácio dos Elementos dá o tom: "Não se trata 
aqui de uma marquesa, nem de uma filosofia imaginária”. Voltaire exige de seu leitor um verdadeiro esforço, pois a ciência de Newton não é um romance da natureza. Mesmo que ele procure a simplicidade e a clareza na exposição, ele quer conservar da ciência de Newton seu caráter complexo. Voltaire, na introdução à física newtoniana, não se endereça a uma marquesa, mas a uma mulher ou a um homem de espírito que ele compara com um ministro: "A ciência da natureza é um bem que pertence a todos os homens. Todos gostariam de ter conhecimento sobre esse bem, poucos têm tempo ou paciência para calculá-los; Newton contou por eles. É preciso se contentar aqui com a soma de seus cálculos. Todos os dias um homem público, um ministro, forma para si uma ideia justa do resultado das operações que ele próprio não pode fazer; outros olhos viram por ele, outras mãos trabalharam, e o colocam em estado de ter seu juízo por meio de uma conta fiel. Todo homem de espírito estará mais ou menos na condição do ministro.”Voltaire apresenta nessa passagem o modelo a seguir para escrever um livro de apresentação da ciência. Esse modelo é o relatório administrativo ou a nota de síntese que permite ao ministro agir sem entrar no detalhe dos cálculos. Pela firmeza de estilo e de intenção da obra,Voltaire procura impor uma nova imagem da ciência que não tem propriamente a ver com o ideal de cultura mundana próprio a Fontenelle e a Algarotti. Trata-se de fazer da ciência uma coisa séria de que se trata seriamente e de lutar contra "esta afetação muito difundida de tratar os assuntos sérios num estilo alegre e familiar [o que] tornaria, com o tempo, a filosofia ridícula, sem torná-la mais fácil”.

Se Voltaire suprimiu os raciocínios geométricos e os cálculos que fazem a força dos Principia, é porque a compreensão deles é reservada aos especialistas que dominam a linguagem matemática necessária para sua compreensão: qual o propósito de traduzir de maneira imperfeita aquilo que Newton diz tão bem em linguagem matemática? Voltaire não procura explicitar os procedimentos próprios à matematização da física. Seu objetivo é reunir os resultados dos cálculos de Newton e torná-los claros. Fazendo isso, ele apresenta ao leitor esses resultados como verdades, pois ele prefere se apoiar sobre a eficácia explicativa da atração do que tentar tornar inteligíveis os raciocínios áridos e algumas vezes obscuros de Newton. O leitor possui somente uma matriz exterior da ciência newtoniana, ele deve remetê-la aos princípios matemáticos que forjam 
suas próprias normas de inteligibilidade e de legitimidade. É preciso aceitar, quando se é uma pessoa de espírito, os limites de seu espírito, como propõe o próprio Newton ao fim do escólio geral dos Principia. Voltaire, grande leitor de Bayle e de Locke, não pode senão aderir a esta confissão de ignorância e a esta exigência de se ater aos fatos. As leis matemáticas que descrevem os fatos e permitem prevê-los têm um sentido operatório e, portanto, uma legitimidade sem que sejam fundamentadas. As perspectivas abertas pela nova ciência são ao mesmo tempo aquelas de um ceticismo crítico e de uma especialização do saber: não somente os limites do espírito impõe a renúncia do saber absoluto, mas, no seio mesmo do saber efetivo, a especialização da linguagem matemática impõe um espaço de discussão acessível somente aos especialistas. Quando Voltaire escreve na conclusão de sua obra: "Nós estamos apenas nas margens de um imenso oceano; quantas coisas restam a descobrir! Mas também quantas estão para sempre fora da esfera de nossos conhecimentos", o "nós" pode designar tanto Newton e os matemáticos newtonianos quanto os leitores de Voltaire, ou seja, os homens de letras e não aqueles de Newton (ou seja, os cientistas). Em outros termos, os Elementos têm por função fazer com que os homens de letras compreendam que a nova ciência tem uma linguagem matemática que lhe é própria, quer dizer, uma fonte de inteligibilidade irredutível à cultura tradicional.

Nesse sentido, a obra de Voltaire tem sentido em seu tempo porque propõe uma nova relação do homem de espírito com a ciência. Essa relação não é somente uma relação de curiosidade ou de fascinação, mas também de profunda exterioridade da ciência como ela é feita. Essa relação é talvez aquela que o poeta Voltaire viveu, ao menos inicialmente, na sua relação com a Marquesa du Châtelet, matemática sem par, é preciso sublinhar. Ele avançou, devido ao trabalho e a leituras, até o espaço de discussão reservado aos iniciados, cujo traço encontramos algumas vezes nos Elementos, no rodeio de uma frase. Efetivamente, quando Voltaire se endereça à marquesa, não é a uma marquesa imaginária, mas a GrabrielleEmilie de Breteuil que discute e trabalha com ele.

O expediente da argumentação de Voltaire reside em estabelecer apenas as grandes questões do sistema do mundo, a saber, as desigualdades do movimento e da órbita da lua, o movimento dos planetas e a estabilidade do sistema solar, a figura da Terra e seu tempo periódico, as marés, os 
cometas, recebem uma explicação de fato satisfatória pelos cálculos e medições dos movimentos terrestres e celestes que a lei da atração permite operar. Voltaire sublinha que essas questões agitaram desde há muito os espíritos, o que lhe dá a oportunidade de apresentar historicamente este ou aquele problema resumindo a posição de Aristóteles, de Tycho Brahé, de Kepler e de Descartes. Nesse sentido, Voltaire não somente faz o trabalho de divulgador do saber nos Elementos, mas também de historiador das ciências, e este aspecto não é de menor interesse. Com efeito, por esta perspectiva da história das ciências, Voltaire marca o caráter universal sincronicamente e diacronicamente - da lei newtoniana de acordo com a qual os corpos se atraem em razão inversa do quadrado de sua distância.

Diacronicamente, a teoria newtoniana da atração é perfeitamente rigorosa, ela está entre as obras que atingem o caráter universal e necessário da verdade científica representada, de acordo com Voltaire, por três personagens: Euclides, Arquimedes e Newton. Voltaire se serve da história das ciências como uma arte de persuadir: a história das ciências torna Newton incontornável. Assim ele escreve:

«Algumas pessoas de espírito [...] dão como desculpa por sua preguiça que não vale a pena se unir a um sistema que passará como nossas modas; ouviram dizer que a escola iônica combateu a escola de Pitágoras, que Platão foi combatido por Epicuro, que Aristóteles abandonou Platão, que Bacon, Galileu, Descartes, Boyle, fizeram cair Aristóteles; que Descartes por sua vez desapareceu, e concluem que virá um tempo em que Newton sofrerá o mesmo destino.

Aqueles que têm esse discurso vago supõe o que é muito falso, que Newton fez um sistema, ele não o fez, ele anunciou apenas verdades da geometria e verdades da experiência. É como se disséssemos que as demonstrações de Arquimedes um dia passarão. Pode ser que um dia alguém descubra a causa do peso. Mas as proposições sobre os pesos e as distâncias de Arquimedes não estarão menos demonstradas, o cálculo que Newton fez da gravitação não será nem menos verdadeiro nem menos admirável.» (Lettre de Voltaire à Maupertuis, 1739, pp. 709-710).

Voltaire, nessa passagem, defende uma concepção da verdade como matematicamente necessária. Newton chegou à verdade porque seus princípios são matemáticos (verdades da geometria) e são aplicados 
rigorosamente aos fatos (verdades da experiência). Por meio da comparação com Arquimedes, ele dá à teoria newtoniana da atração o estatuto de um teorema (a atração tem o mesmo valor matemático de verdade que as proposições demonstradas dos pesos e das distâncias). Dito de outra forma, os sistemas se sucedem na história até que um gênio como Euclides, como Arquimedes ou como Newton chegue à verdade necessária.

Sincronicamente, os Elementos da Filosofia de Newton bastam para provar, para Voltaire, o caráter universal de eficiência causal da atração, pois todos os fenômenos nele descritos devem ser considerados como seus efeitos.

A conclusão do último capítulo reflete perfeitamente o propósito de universalidade que Voltaire persegue: "Vê-se que todos os fenômenos da natureza, as experiências e a geometria concorrem por todos os lados para estabelecer a atração.Vê-se que esse princípio age de uma ponta a outra de nosso mundo planetário, sobre Saturno e sobre o menor átomo de Saturno, sobre o Sol e sobre o menor raio de Sol. Esse poder tão ativo e tão universal não parece dominar toda a natureza, não é ele a causa única de muitos efeitos, não se mistura ele a todos os outros recursos com os quais a natureza opera?" (VOLTAIRE, 1992, p. 530).

O que faz todo o interesse da obra de Voltaire se deve ao fato que as questões epistemológicas recobrem também questões ideológicas.Voltaire procura confrontar o espírito de sistema e o espírito de partido desenvolvendo uma concepção universal e necessária da verdade representada por Euclides, Arquimedes e Newton. ${ }^{1}$ Ele procura combater uma concepção nacionalista da verdade. Por diversas vezes, em particular na Réponse à toutes les objections, ele se defende da acusação de ser mau cidadão francês porque defende Newton, um inglês, contra o francês Descartes. Jean Banières, notadamente, o acusou de ter pecado contra sua pátria. Na carta a Maupertuis de 1739, Voltaire escreve a propósito de Descartes: «É, portanto, muito injusto que me acusem de crime por combatê-lo, como se fosse a ação de um mau francês[...] E o que importa que a verdade venha da Bretanha, da Provença ou de Cambridge, bom cidadão é quem a busca em todos os lugares em que está». Voltaire chega mesmo a retrucar a acusação afirmando diversas vezes que ele escreve para os franceses: «O quê! Os nomes de Descartes e Newton tornaram-se nomes de disputa! Somos passionais quando deveríamos apenas nos instruir. Quê importam os nomes! Quê importam os lugares onde as verdades 
foram descobertas! Trata-se de experiências e cálculos, e não de chefes de partido.». Compreende-se, através de o discurso de Voltaire que os conflitos políticos e econômicos que opõem a França à Inglaterra nesta época não deixam de influenciar o debate entre cartesianos e newtonianos e explicam talvez em parte a resistência dos cartesianos em receber a teoria newtoniana na França. $\mathrm{Na}$ boca daquele que se declara ser cidadão do mundo ou que pergunta na Réponse à toutes les objections: «Há então estrangeiros para um filósofo?» (Éléments, p. 736), não tem nada de surpreendente a intenção segundo a qual é preferível uma demonstração ao espírito de sistema, ou melhor, de seita.

Voltaire é certamente, nesse sentido, uma figura das Luzes. A filosofia, a ciência e a verdade não têm partido ou pátria, são universais e devem servir de arma para esmagar a infame, ou seja, todas as formas de superstição e de fanatismo que tem o povo sob a tutela de padres e reis. Lembremos aqui que dois casos nos anos 60 dão ocasião para Voltaire empreender um verdadeiro combate pela verdade. O caso Calas é a história de um erro judiciário resultado da intolerância religiosa: em 13 de outubro de 1761, o mais velho de seis filhos de Jean Calas, Marc-Antoine, se enforca. Os pais cometem a imprudência, para evitar a desonra, de esconder o suicídio. A justiça então acusa o pai Jean, calvinista, de ter matado seu filho porque este teria manifestado sua intenção de se converter ao catolicismo. Em virtude de um decreto do Parlamento de Toulouse, Calas foi quebrado vivo sobre a roda em 1762. Voltaire acolheu em Ferney a viúva e dois de suas crianças, as outras três foram levadas a conventos. Ele obteve um decreto do Conselho do Rei que cassava aquele de Toulouse e anunciava a reabilitação de Jean Calas em 1765.

O segundo caso é o do Cavaleiro de la Barre. Esse jovem, nascido em Abbeville, em 1747, foi acusado de ter destruído um crucifixo e ter proferido algumas blasfêmias, foi preso junto de outros três jovens, todos suspeitos de não terem descobertos suas cabeças por ocasião da passagem do santo sacramento em 1765. O cavaleiro de La Barre foi condenado pelo tribunal de Abbeville a ter seu pulso cortado, sua língua arrancada e depois ser levado à fogueira. Ele recorreu ao parlamento de Paris, que ordenou que ele fosse decapitado antes de ser queimado. Morreu com coragem. Reclamada em vão por Voltaire, sua reabilitação foi decretada pela Convenção em 1793. 
O que reter desse combate de Voltaire pela verdade e desta história de Voltaire, da Marquesa e de Newton? Em que sentido o caminho de Voltaire pode fornecer elementos para a resposta à minha segunda questão: por que refletir sobre as ciências? Quando ponho a questão a Voltaire, a resposta parece clara: pelo gosto do universal, para fazer triunfar a verdade fora das fronteiras e assim trabalhar para a liberdade de pensar. Mas não é esta a resposta das Luzes? Não é justamente ela posta em questão pelos erros do positivismo e do cientificismo que podemos resumir nesta fórmula: fora da ciência, nenhuma salvação? Não temos razão de, no século XXI, desconfiar da ciência? No momento em que os recursos naturais se escasseiam devido à exploração desmedida dos homens e, no entanto, permitida pelo progresso técnico e científico, no momento em que a ciência experimental mergulha nas águas turbulentas da clonagem, no momento em que o homem é o predador de todo o planeta, não temos razão em desconfiar da ciência e até mesmo responsabilizá-la por todos os males? É isto que alguns querem nos fazer crer. A ciência e seus rebentos, as técnico-ciências, fazem a infelicidade dos homens. Esta posição não é nova, Rousseau já a defendia no coração das Luzes, mas ela é partilhada por um número cada vez maior de pessoas. Isso tem a ver com o fato de que o ódio pelas ciências e as técnicas foi e continua a ser favorecido pela cisão institucional entre as ciências e as letras. Aquilo que chamamos hoje de cultura está pouco ou nada conectada com as ciências. Aquilo que tem a ver com a ciência é totalmente ignorado por uma grande parte da opinião. Afora alguns lances midiáticos sobre tal vacina ou tal planeta, nada se sabe e nada se compreende daquilo que nos rodeia: por que o mar é azul? Por que ele é salgado? Como se formaram os oceanos? Por que as estrelas continuam a brilhar após sua explosão? Por que a neve forma flocos? Tantas questões que permanecem em suspenso, pois não se sabe onde e como encontrar as respostas. $\mathrm{O}$ que dizer àqueles que são refratários em relação à ciência? Talvez contar a eles outra história, desta vez um pesadelo. Esta história, devemos dizer, é uma ficção, aquela imaginada por George Orwell em 1984. Mas antes de analisar a cena que coloca Winston, a vítima do sistema totalitário, e O’Brien, seu algoz, chefe do Partido do Grande Irmão, eu gostaria de lembrar outra história, esta vivida, e que servirá de introdução à cena de Orwell. 
Esta história real é a de Primo Levi, um cientista, algo em larga medida ignorado, pois ele é sobretudo conhecido como um grande escritor humanista, autor de Se é isto um homem, diário de sua deportação publicado em 1947 e que é um dos primeiros testemunhos de Auschwitz. Em sua última obra autobiográfica, O sistema periódico, escrito em 1975, Primo Levi conta por que em 1939, ele considerava os estudos de fisica e de química como um remédio aos miasmas do fascismo, porque «elas eram claras e distintas, verificáveis a cada etapa, e não enlaçadas por mentiras e vaidade como a rádio e os jornais». Estudando a física e a química, Levi se sentia livre não no sentido de que nada lhe fazia obstáculo (o que seria da pesquisa científica se as soluções a um problema aparecessem todas prontas?), mas no sentido de que seu espírito, na busca da descoberta científica, não estava submetido à boa vontade de outro. Sua experiência da forma primordial de liberdade em seus estudos científicos se devia ao fato que as dificuldades e os obstáculos que ele encontrava não eram o produto de uma vontade alheia e que lá não havia nenhuma negociação possível com este ou aquele, nem estratégia para evitá-los. Ora, ser livre, no sentido mais simples, mais claro e mais clássico do termo, não quer dizer não estar submetido à vontade de outro? Como diz o próprio Primo Levi, na ciência concedemos tal importância aos resultados experimentais que compreendemos com uma força particular que entregamo-nos a um combate contra algo que é diferente de nós mesmos. O sentimento de liberdade que desfrutava Primo Levi em 1939 fazendo física ou química vem dessa coisa extremamente simples, a saber, que as regularidades dos movimentos dos planetas e dos corpos em geral não é regido por nenhum poder humano. Dito de outra forma, elas não são manipuláveis à vontade, e as leis científicas que exprimem essas regularidades constituem os conhecimentos «não manipuláveis».

É exatamente neste ponto que devem entrar em cena Winston e O’Brien, os personagens de 1984. Por quê? Porque Orwell leva ao paroxismo a tensão entre aquilo que um homem conhece como cientificamente verdadeiro e aquilo que se procura fazer com que ele creia e reconheça como verdadeiro. O’Brien, o chefe do partido da tortura, exercerá seu poder sobre Winston lhe obrigando a dizer coisas falsas. Reaparece aqui de certa forma o processo de Galileu, mas hipertrofiado porquanto visto e corrigido pelo olhar do Grande Irmão. 
Winston é um resistente, ele traz um diário em suas mãos no qual anota: "A liberdade é a liberdade de dizer que dois mais dois são quatro. Concedido isto, todo o resto se segue». O que importa é o direito de dizer aquilo que sabemos verdadeiro. Nesse sentido, os Inquisidores sabiam o que faziam quando, após a retratação de Galileu perante o tribunal do Santo Ofício, deixaram-no viver, mas preso e vigiado em sua casa, com a proibição de ensinar, de receber e enviar correspondências. Galileu foi condenado em 1633 e foi calado até 1642: aos olhos da Inquisição, ele já não representava qualquer perigo. Compreende-se então como a liberdade de pensar a verdade é essencialmente a liberdade de poder partilhá-la.

É este também o significado do ato de resistência de Winston com seu diário: ele escreve para ser lido, para partilhar aquilo que sabe ser verdadeiro independentemente de toda propaganda e de toda manipulação. E, precisamente, aquilo que não é manipulável para Winston é a cultura científica, é o conhecimento adquirido por meio da prova e da demonstração. Aquilo que não é manipulável para Winston é dizer que dois e dois são quatro assim como para Galileu é dizer que a Terra gira. Orwell chega mesmo a sustentar, em seu romance, que a simples liberdade interior não é a verdadeira liberdade porque aquilo que pensamos sem ter o direito de dizer pode ser apenas ilusão.

Aqui ganha todo o seu sentido a cena horrível imaginada por Orwell, quando o chefe do Partido, O’Brien, força Winston pela tortura a dizer que dois mais dois são cinco. Winston acaba dizendo, mas diz da mesma maneira como diria aquilo que sabe verdadeiro? Não, a tortura não produz qualquer convicção, ela produz sofrimento, humilhação, ódio e uma perda de identidade. É justamente isto que quer O'Brien, ele quer partir Winston em sua identidade mais forte, aquela que o faz resistir ao totalitarismo do Grande Irmão, aquela que faz com que ele traga seu diário. É este desejo que O'Brien quer destruir. Ora, este desejo Winston conseguiu preservar por meio dos conhecimentos não manipuláveis que adquiriu ao mesmo tempo em que adquiriu o senso do real, um real diferente de si, um real cuja força de resistência ao demasiado humano, ao humano inumano, ele conhecia. Nesse mundo de vigilância e de engodos permanentes, nesse mundo revisionista em que a história é constantemente corrigida para dar razão ao Grande Irmão em suas previsões erradas, a única força de resistência à perda de identidade e de sentido, para Winston, é a 
força de escrever clandestinamente um diário e de dizer que dois e dois são quatro ou que a Terra gira.

Esta história de pesadelo de Winston e o testemunho de Primo Levi reencontram a resposta de Voltaire à questão: Por que refletir sobre as ciências? Por quê? Para viver sobre um fundo de verdade e não de mentira, para construir um sentido do real que seja universal e partilhável. É preciso partilhar este sentido do real precisamente porque ele é irredutivel ao Homem e a seus limites representados, nos exemplos que desenvolvi, por uma concepção religiosa ou nacionalista da verdade ou por uma ideologia totalitária perversa e destrutiva. Pois, no fundo, aquilo que nos ensinam, cada um a seu modo, Galileu, Voltaire, Primo Levi ou Orwell por meio de seu personagem Winston, é que o mais precioso no Homem é ter o desejo da verdade a qualquer preço, de ter o desejo de atingir aquilo que é verdadeiro e de dizê-lo.

E este bem mais precioso o é a qualquer custo, mesmo ao custo de reconhecer que a ciência e a filosofia repousam sobre um desejo que jamais será realmente satisfeito, porquanto o real resiste às investigações dos seres humanos. $\mathrm{O}$ sentido que mulheres e homens projetam sobre o real não o capta completamente, felizmente, pois que sentido restaria à vida humana? É isto que Voltaire compreendeu perfeitamente e que ele relembra na última dúvida do Filósofo ignorante: não se deve abster de alimentos com o medo de estarem envenenados, da mesma maneira que não se deve abster da busca da verdade com medo de ser perseguido. O desejo de saber, o desejo de buscar a verdade é aquilo que há de mais precioso, mesmo que saibamos que a verdade é como um sol que recua à medida que avançamos. Pouco importa que saibamos que jamais chegaremos ao sol, o essencial é persegui-lo.

${ }^{1}$ Voir Éléments, p. 401 et pp. 709-710.

\section{Referências bibliográficas}

VOLTAIRE. 1992. Éléments de la philosophie de Newton, tome XV des Euvres complètes de Voltaire, critical edition by R.L. Walters and W.H. Barber. The Voltaire Foundation Taylor Institution, Oxford. 
128

0 0 